\title{
The differences of gonadal hormones and uterine transcriptome during shell calcification of hens laying hard or weak- shelled eggs
}

\author{
Jiacai Zhang, Yanan Wang, Cong Zhang, Mingxin Xiong, Shahid Ali Rajput, Yun Liu and Desheng Qi* (D)
}

\begin{abstract}
Background: Eggshell breaking strength is critical to reduce egg breaking rate and avoid economic loss. The process of eggshell calcification initiates with the egg entering the uterus and lasts about $18 \mathrm{~h}$. It follows a temporal sequence corresponding to the initiation, growth and termination periods of shell calcification. During each period of shell calcification, our study investigated the differences of gonadal hormones and uterine transcriptome in laying hens producing a high or low breaking strength shell.

Results: $60 \mathrm{Hy}$-line Brown laying hens were selected and divided into two groups according to eggshell breaking strength. Eggshell breaking strength of $44.57 \pm 0.91 \mathrm{~N}$ and $26.68 \pm 0.38 \mathrm{~N}$ were considered to be the high strength group (HS) and low strength group (LS), respectively. The results showed that mammillary thickness and mammillary knob width of eggshells were significantly lower in the HS. Serum progesterone $\left(\mathrm{P}_{4}\right)$ and 1,25-dihydroxy vitamin $D_{3}\left[1,25-(\mathrm{OH})_{2} \mathrm{D}_{3}\right]$ were significantly higher in the HS compared to the LS during the initiation period of calcification. Serum estradiol $\left(E_{2}\right)$ and calcium did not change significantly. All factors mentioned above had no significant differences in the growth and termination periods of calcification. The relative expression of $C a B P-D_{28 k}$ and PMCA $1 \mathrm{~b}$ were not significantly different between HS and LS. The relative expression of NCX1 was significantly higher in HS compared to LS. Moreover, 1777 differentially expressed genes (DEGs) were obtained in the initiation period of calcification. However, few DEGs were identified in the growth or termination periods of calcification. 30 DEGs were selected as candidate genes involved in eggshell calcification during the initiation period of calcification by the analysis of $\mathrm{GO}$ terms and KEGG pathways.
\end{abstract}

Conclusions: Our study concluded that mammillary thickness and mammillary knob width of the HS were significantly lower than LS. $\mathrm{P}_{4}$ and $1,25-(\mathrm{OH})_{2} \mathrm{D}_{3}$ were significantly higher in the initiation period of HS. They may impact initial calcification when the mammillary layer is formed. The initiation period of calcification determined eggshell strength rather than the growth or termination periods. We inferred $\mathrm{P}_{4}$ or $1,25-(\mathrm{OH})_{2} \mathrm{D}_{3}$ may effect the ultrastructure of the mammillary layer by regulating the expression of uterine genes.

Keywords: Gonadal hormone, Transcriptome, Eggshell, Laying hen, lon transport

\footnotetext{
* Correspondence: qds@mail.hzau.edu.cn

College of Animal Nutrition and Feed Science, Huazhong Agricultural

University, Wuhan 430070, Hubei, China
}

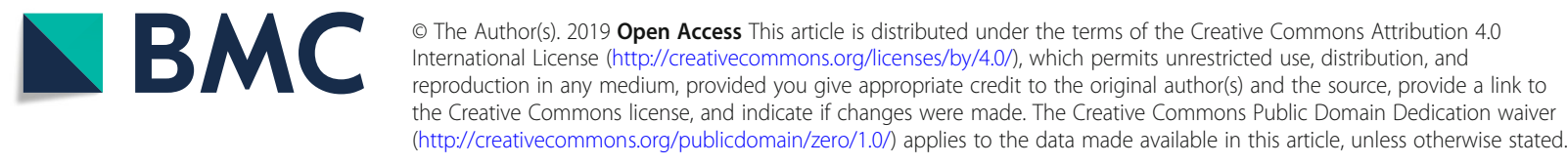




\section{Introduction}

The eggshells of laying hens are a composite bioceramic material containing 95\% calcium carbonate as polymorphic calcite and $3.5 \%$ organic matrix proteins [1]. The eggshell provides mechanical protection for embryonic development and prevents microbial invasion. The calcium needed for embryonic development is produced mainly by the eggshell. The most common problem of eggshells in production is the defect rate, which increases with the age of the hens. Eggshell quality is one of the most important concerns in the poultry industry, greatly affecting profits. Eggs with low breaking strength are easily damaged during collection, storage, and transportation. On average, broken eggs account for $7.5 \%$ [2], which can lead to significant economic losses. The eggshell is formed in the uterus which is a segment of the oviduct of laying hens. The process of eggshell formation is divided into three crucial periods: initiation of crystal growth, linear crystal growth, and termination of mineralization [3]. The eggshell consists of a bilayered membrane, mammillary layer, palisade layer, vertical crystal layer, and cuticle layer [4]. Many researchers have proposed that differences in eggshell ultrastructure exist between high and low strength eggshells [5-7]. The ultrastructure of eggshell is related to matrix proteins that regulate morphology, growth kinetics, and crystallographic orientation of calcite crystals $[8,9]$, such as ovocleidin-116 [10], ovocleidin-17 [11], ovocalyxin-32 [12], and ovocalyxin36 [13]. These proteins have been shown to be involved in the biomineralization of the eggshell [14].

To improve eggshell quality, many studies have investigated calcium and trace elements in the diet. However, increasing dietary calcium levels did not improve eggshell quality [15]. Manganese enhanced the synthesis of glycosaminoglycan in the eggshell membrane, which contributed to eggshell strength [16]. Zinc is a component of the enzyme carbonic anhydrase, which is essential for the formation of calcium carbonate [17]. Zinc supplementation increased eggshell thickness rather than eggshell strength [18]. The simultaneous supply of zinc and manganese in the diet increased eggshell strength from 33.5 to $36.7 \mathrm{~N}$ in the late phase of the laying cycle (70 weeks of age), while it had no effect in young laying hens (35 weeks of age) [19]. This conclusion was supported by Świątkiewicz et al. [20]. Moreover, Kim et al. reported that magnesium increased the eggshell strength from 3.1 to $3.4 \mathrm{~kg} / \mathrm{cm}^{2}$ in 72-week-old laying hens [21]. Furthermore, copper has also been shown to affect eggshell quality [22]. Copper promoted desmosine formation in the shell membrane by activating amine oxidase [23]. Although the data from these studies were statistically significant, the author believed that the improvement in eggshell quality was minor. The improved eggshell strength from supplemental trace elements is much lower than the eggshell strength obtained in young hens.
It has been reported that exogenous estrogen improved eggshell quality and progesterone injected prolonged the period of eggshell formation [24]. Progesterone inhibited calcium ion transport and the concentration of calbindin mRNA in the eggshell gland [25]. Another study reported that the eggshell thickness of domestic fowls was increased following administration of mifepristone, an anti-progesterone compound [26]. Interestingly, a high incidence of hens producing hard-shelled uterine eggs was observed following progesterone injection [27]. Thus, we hypothesized that gonadal hormones may impact eggshell strength. However, the mechanisms are unclear. This study investigated the differences in gonadal hormone levels and the gene expression profile of the uterus during the three pivotal mineralization periods (initiation, growth, and termination) of eggs with a high or low breaking strength.

\section{Results}

Mechanical property parameters of the eggshell

Mechanical property parameters of the eggshell are provided in Table 1. A transverse views of eggshell ultrastructure are shown in Additional file 1. Breaking strength, eggshell thickness, and shell ratio of the HS were significantly higher compared to the LS $(P<0.05)$. However, the egg shape index was not significantly different $(P>0.05)$. Compared with the LS, mammillary thickness, mammillary knob width, and mammillary layer ratio were significantly lower in the HS $(P<0.05)$. Furthermore, the effective thickness and effective layer ratio were significantly higher in the HS $(P<0.05)$. The eggs in the uterus of each calcification period (initiation, growth, and termination) and the laid egg are shown in Additional file 2.

\section{Concentration of hormones and calcium in the serum}

The levels of $\mathrm{P}_{4}, \mathrm{E}_{2}, 1,25-(\mathrm{OH})_{2} \mathrm{D}_{3}$, and $\mathrm{Ca}^{2+}$ are shown in Table 2. Compared with the LS, the concentration of $\mathrm{P}_{4}$ and 1,25- $(\mathrm{OH})_{2} \mathrm{D}_{3}$ in the HS were significantly higher in the initiation period but did not change significantly

Table 1 Mechanical property parameters of eggshell in $\mathrm{LS}$ and $\mathrm{HS}^{1}$

\begin{tabular}{lll}
\hline Parameters & LS & HS \\
\hline Breaking strength, N & $26.68 \pm 0.38$ & $44.57 \pm 0.91^{*}$ \\
Eggshell thickness, mm & $0.359 \pm 0.003$ & $0.391 \pm 0.003^{*}$ \\
Egg shape index & $1.29 \pm 0.006$ & $1.28 \pm 0.006$ \\
Shell ratio, \% & $9.43 \pm 0.001$ & $10.25 \pm 0.001^{*}$ \\
Mammillary thickness, $\mu \mathrm{m}$ & $99.09 \pm 3.57$ & $60.00 \pm 1.63^{*}$ \\
Mammillary knob width, $\mu \mathrm{m}$ & $83.23 \pm 4.20$ & $56.82 \pm 2.56^{*}$ \\
Effective thickness, $\mu \mathrm{m}$ & $239.09 \pm 8.14$ & $288.64 \pm 5.06^{*}$ \\
Mammillary layer ratio, \% & $29.41 \pm 1.15$ & $17.21 \pm 0.35^{*}$ \\
Effective layer ratio, \% & $70.59 \pm 1.15$ & $82.79 \pm 0.35^{*}$ \\
\hline
\end{tabular}

${ }^{1}$ Results are reported as the mean \pm SEM

*Means within a row significantly differ compared to the LS $(P<0.05)$ 
Table 2 The concentrations of gonadal hormones and calcium in serum from $\mathrm{LS}$ and $\mathrm{HS}^{1}$

\begin{tabular}{llll}
\hline Parameters & Period & $\mathrm{LS}$ & $\mathrm{HS}$ \\
\hline $\mathrm{P}_{4}, \mathrm{pmol} / \mathrm{L}$ & Initiation & $752.55 \pm 118.09$ & $1401.63 \pm 155.53^{*}$ \\
& Growth & $656.33 \pm 100.56$ & $605.23 \pm 80.16$ \\
& Termination & $751.30 \pm 134.07$ & $616.66 \pm 93.66$ \\
$\mathrm{E}_{2}, \mathrm{pg} / \mathrm{mL}$ & Initiation & $251.17 \pm 39.43$ & $296.61 \pm 59.70$ \\
& Growth & $243.41 \pm 39.72$ & $166.82 \pm 24.02$ \\
& Termination & $335.46 \pm 58.20$ & $221.92 \pm 28.17$ \\
$1,25-(\mathrm{OH})_{2} \mathrm{D}_{3}, \mathrm{ng} / \mathrm{mL}$ & Initiation & $22.90 \pm 4.13$ & $40.22 \pm 6.89^{*}$ \\
& Growth & $21.59 \pm 3.78$ & $19.20 \pm 3.22$ \\
& Termination & $24.26 \pm 5.22$ & $19.79 \pm 3.77$ \\
$\mathrm{Ca}, \mu \mathrm{g} / \mathrm{mL}$ & Initiation & $335.58 \pm 9.74$ & $261.29 \pm 15.42^{*}$ \\
& Growth & $201.67 \pm 17.64$ & $196.81 \pm 9.67$ \\
& Termination & $266.98 \pm 17.37$ & $239.03 \pm 10.41$ \\
\hline
\end{tabular}

${ }^{1}$ Results are reported as the mean \pm SEM

*Means within a row significantly differ compared to the LS $(P<0.05)$

in the growth or termination periods. However, the blood calcium level in the LS in the initiation period was significantly higher compared to the HS. The concentration of $E_{2}$ did not change significantly in the calcification period.

\section{Expression levels of genes in the duodenum}

Primers targeting CaBP- $\mathrm{D}_{28 \mathrm{k}}$, MPCA $1 \mathrm{~b}$, and NCX1 were designed by primer 5.0 (Additional file 3 ). The relative expression levels are shown in Fig. 1. These genes impact the translocation efficiency of calcium ions in the duodenum. No significant differences were apparent in the relative expression levels of PMCA 1b (Fig. 1a) and CaBP-D ${ }_{28 k}$ (Fig. 1b) in the calcification period. In the growth and termination periods, the relative expression level of NCX1 (Fig. 1c) in the HS was significantly higher compared with LS. However, there was no difference in the expression of NCX1 in the initiation period.

\section{Differential transcriptome expression in the uterus}

The mRNA expression profile was investigated in the uterus of both HS and LS. DEGs were initially identified by fold change $>1.5$ and $P<0.05$ (Additional file 4). In the initiation period of calcification, 1777 annotated genes were significantly different in the uterus (Fig. 2a). Of the 1777 genes, 685 genes were upregulated and 1092 genes were downregulated (HSI vs. LSI). However, in the growth period of calcification, only 16 genes were identified as DEGs (Fig. 2b), which included 12 upregulated and 4 downregulated genes (HSG vs. LSG). A similar trend existed in the termination period of calcification in which eight genes were considered differentially expressed (Fig. 2c). Of these genes, three were upregulated and five were downregulated (HST vs. LST). From the results, it conclude that the initiation period of calcification is the most critical period for determining the mechanical properties of eggshells. Thus, in subsequent experiments, only the RNA-Seq data in the initiation period of calcification were analyzed.

DEGs of the initiation period were enriched in biological process, cellular component, and molecular function categories by GO analysis (http://www.geneontology.org/). GO terms with $P<0.05$ were considered significantly enriched in DEGs. The GO term enrichment analysis showed that the highest enrichment of DEGs in biological process, cellular component, and molecular function were chemical homeostasis, extracellular space, and sodium channel activity, respectively (Fig. 3). DEGs were also plotted to KEGG reference pathways (https://www.kegg.jp/ kegg/pathway.html); 87 KEGG pathways of chicken were assigned. The significantly enriched KEGG pathways $(P<$ $0.05)$ are listed in Table 3. Of these KEGG pathways, the calcium signaling pathway has been reported to be linked to calcium metabolism in the uterus. In addition to calcium ions $\left(\mathrm{Ca}^{2+}\right)$, bicarbonate ions $\left(\mathrm{HCO}_{3}{ }^{-}\right)$are also required for the calcification of eggshells. The expression of a large number of ion transporter genes was significantly different, while the pathway of ion transport from blood to uterine fluid of chicken was not identified in the KEGG pathway database. Therefore, we studied ion transport genes based on previous reports [28-30]. A total of 30 relevant DEGs were selected and some were used to confirm the accuracy of the RNA-Seq data. The functions of the selected genes are listed in Table 4 .

\section{RT-qPCR analysis}

The relative expression of 12 genes, evaluated by RTqPCR, was used to validate the RNA-Seq data. The primers used are listed in Additional file 5. Pearson correlation analysis was used and the Pearson coefficient was $\mathrm{R}=0.920$ with significant correlation $(P<0.0001)$, which was evaluated using $\log _{2}$ fold changes of RNA-Seq values (Additional file 6). The analysis confirmed the accuracy and reproducibility of the RNA-Seq results.

\section{Discussion}

When eggshells are calcified in the uterus, large amounts of calcium ions and matrix proteins are required. Calcium metabolism and uterine proteins differ during the calcification periods (initiation, growth, and termination). Eggshell quality is determined by its ultrastructure [31], especially the palisade layer [32]. Therefore, many studies have focused on the growth period when the palisade layer is formed [29, 33]. However, the mammillary layer, which is formed during the initiation period of calcification, is also closely related to eggshell quality [34]. Therefore, our research was carried out in the initiation (HSI and LSI), growth (HSG and LSG), and termination (HST and LST) 


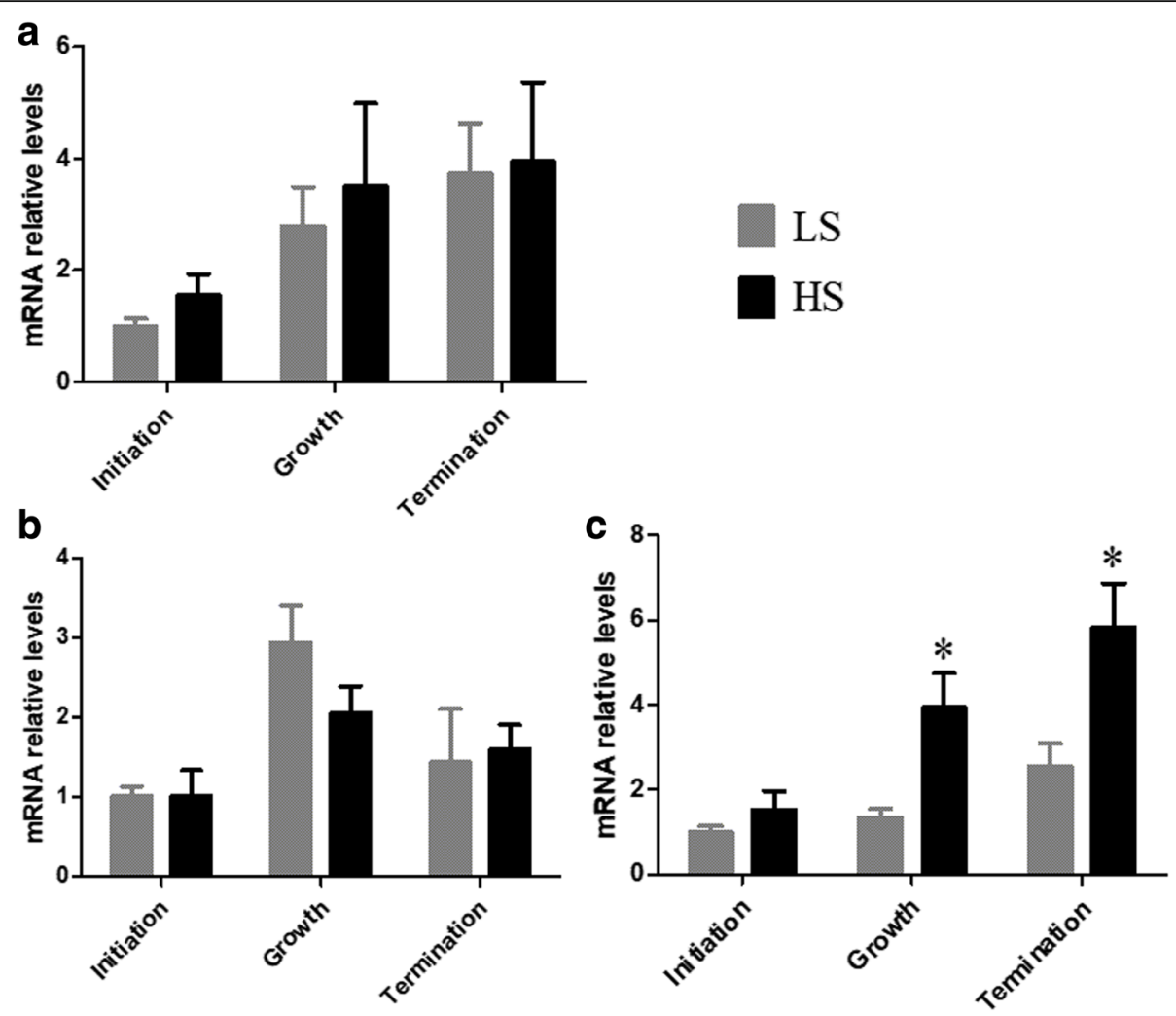

Fig. 1 Relative expression levels of calcium ion transport-related genes in the duodenum. a PMCA1b; (b) CaBP-D $28 k i$ (c) NCX1. The initiation period of LS is set at 1.0. Values are means \pm SEM. Means with * are obviously different from the LS in the same calcification period $(P<0.05)$

periods. Hormones related to calcium metabolism were detected in the blood. Differences in gene expression were identified in the uterus of the HS and LS. In the present study, compared with the LS, mammillary thickness and mammillary knob width in the HS were significantly lower, which is consistent with the previous report [6]. This indicated that the initiation period of calcification, as well as the growth period, is important for eggshell quality. The quality and ultrastructure of eggshells indicated the validity of grouping according to eggshell strength. The different appearance of eggs removed from the uterus after different oviposition times by manual dissection indicated the validity of the three calcification periods.

\section{Serum hormones related to calcium metabolism}

$1,25-(\mathrm{OH})_{2} \mathrm{D}_{3}$ is synthesized from $25-(\mathrm{OH}) \mathrm{D}_{3}$ in the kidney through the catalysis of $1 \alpha$-hydroxylase and regulates duodenal calcium absorption. The laying hens metabolize sufficient $1,25-(\mathrm{OH})_{2} \mathrm{D}_{3}$ from dietary vitamin $\mathrm{D}_{3}$ to maintain shell quality [25]. Hens forming uncalcified shells synthesized less $1,25-(\mathrm{OH})_{2} \mathrm{D}_{3}$ [35]. In previous report, 1,25- $(\mathrm{OH})_{2} \mathrm{D}_{3}$ increased in the growth period of calcification [36]. However, our results showed 1,25$(\mathrm{OH})_{2} \mathrm{D}_{3}$ increased in the HS during the initiation period of calcification. Moreover, serum levels of calcium in the initiation period of LS were significantly higher, which may be a result of inhibition in calcium ion transport.

$\mathrm{P}_{4}$ and $\mathrm{E}_{2}$ are key reproductive hormones for ovulation. Serum $\mathrm{P}_{4}$ showed the peak level at $4-6 \mathrm{~h}$ before ovulation and then quickly declined to basal level [37]. Similarly, serum $\mathrm{E}_{2}$ also showed the peak level at 2-6h before ovulation and then returned to basal level [38]. A few studies have shown that $\mathrm{P}_{4}$ and $\mathrm{E}_{2}$ are related to eggshell quality. Eggshell thickness has been increased by $E_{2}$ injection [25]. However, Bar et al. believed the effect of $E_{2}$ on the synthesis of calbindin mRNA in the eggshell gland were minor. Oral administration of mifepristone (RU38486), an anti-progesterone compound, increased eggshell thickness [26]. On the other hand, the effect of $\mathrm{P}_{4}$ injection on eggshell calcification was related to oviposition time. $\mathrm{P}_{4}$ injected increased shell weight 4 or $10 \mathrm{~h}$ after oviposition and shell weight declined $16 \mathrm{~h}$ after oviposition [39]. Our results showed that $\mathrm{P}_{4}$ level of the HS were significantly higher than the LS, suggesting that $\mathrm{P}_{4}$ may regulate eggshell quality during the initiation period of calcification. However, $\mathrm{E}_{2}$ did not differ significantly during any calcification periods. 


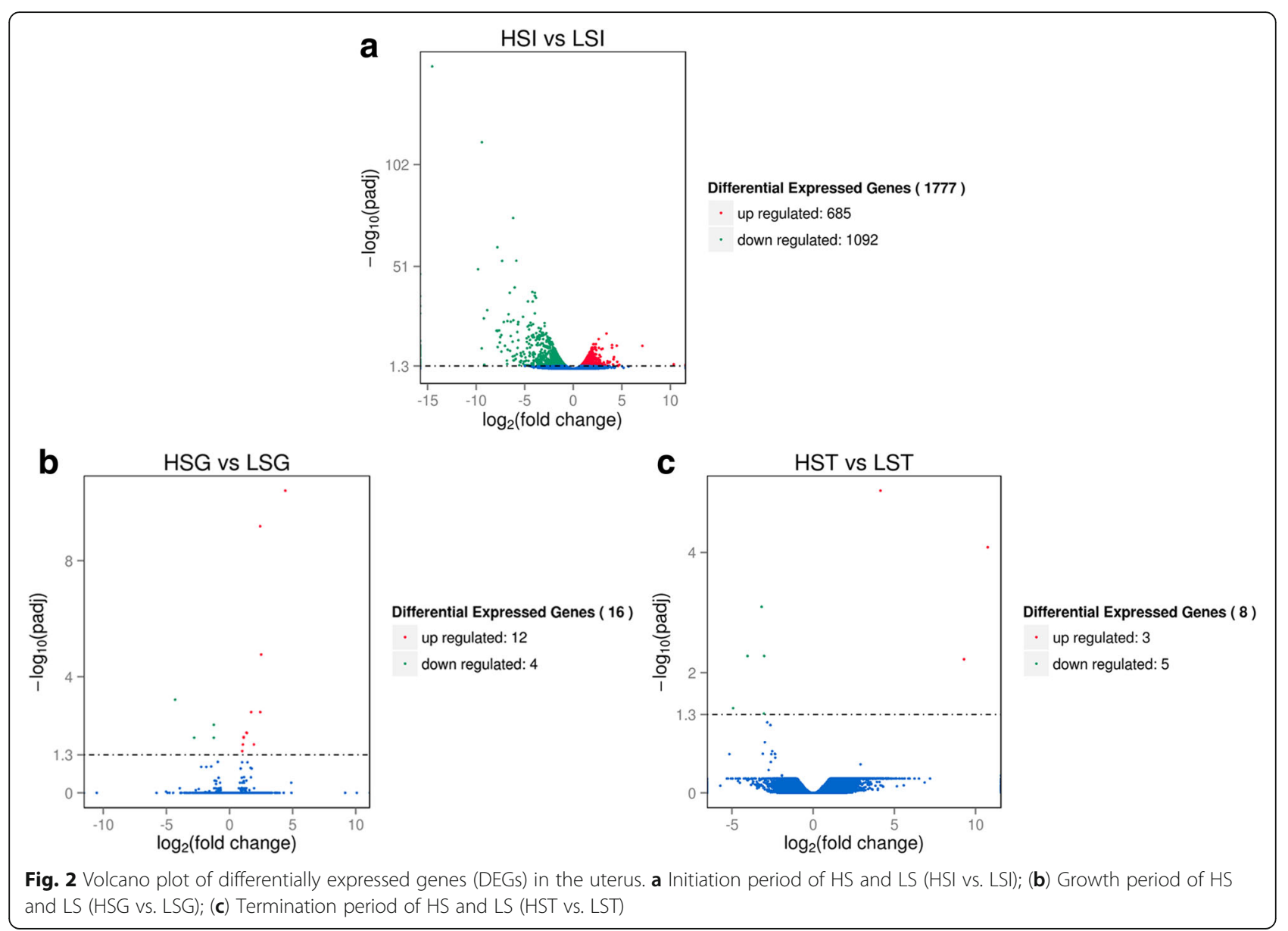

\section{$\mathrm{Ca}^{2+}$ transport in the duodenum}

Dietary calcium is primarily absorbed in the duodenum. The calcium level has a great influence on eggshell quality. Eggshell quality increased when dietary calcium was increased from 1.5 to $2.5 \%$, while no significant differences were observed in these variables between 2.5 and $3.5 \%$ calcium levels [40]. This is consistent with the results of Swiatkiewiz et al., in which eggshell quality parameters were not improved significantly when dietary calcium was increased from 3.2 to $4.2 \%$ [15]. These studies demonstrated that eggshell quality was improved by increasing the calcium level in calcium deficient diets rather than in adequate calcium diets. Our study examined the relative expression levels of genes in the duodenum involved in calcium ion absorption, including calbindin $\left(\mathrm{CaBP}-\mathrm{D}_{28 \mathrm{k}}\right), \mathrm{Na}^{+} / \mathrm{Ca}^{2+}$ exchanger (NCX1), and ATPase plasma membrane $\mathrm{Ca}^{2+}$ transporter (PMCA1b). CaBP$\mathrm{D}_{28 \mathrm{k}}$ and PMCA1b were not differentially expressed in the same calcification period. This indicated that the absorption of $\mathrm{Ca}^{2+}$ in the duodenum had no significant effect on eggshell quality. This was similar to the conclusion of Yosef et al. whose research showed that duodenal CaBP- $\mathrm{D}_{28 \mathrm{k}}$ expression of aged hens (675 and 645 days, respectively) was not significantly different from that of young hens (307 and 245 days, respectively) [41]. Furthermore, eggshell quality was improved after moulting, while duodenal $\mathrm{CaBP}-\mathrm{D}_{28 \mathrm{k}}$ expression did not exhibit a significant change. Although some studies have proposed different views [42], more researchers support the notion that duodenal $\mathrm{CaBP}-\mathrm{D}_{28 \mathrm{k}}$ expression does not effect eggshell quality [43]. In the growth and termination periods of calcification, NCX1 was significantly higher in the HS while had no significant change in the initiation period. This is likely a result of the large amount of $\mathrm{Ca}^{2+}$ needed in the growth and termination periods of calcification.

\section{Uterine gene expression in the initiation period}

Eggshells show a highly ordered structure from deposition of $\mathrm{CaCO}_{3}$ and matrix proteins. A large amount of $\mathrm{Ca}^{2+}$ and $\mathrm{HCO}_{3}{ }^{-}$are required to form $\mathrm{CaCO}_{3}$. Matrix proteins regulate the calcite crystal structure and are secreted by uterine glandular cells into the uterine fluid. $\mathrm{Ca}^{2+}$ and $\mathrm{HCO}_{3}{ }^{-}$are transported from the blood to the uterine fluid through uterine glandular cells by ion transporter proteins. The transcriptome of uterine tissue 


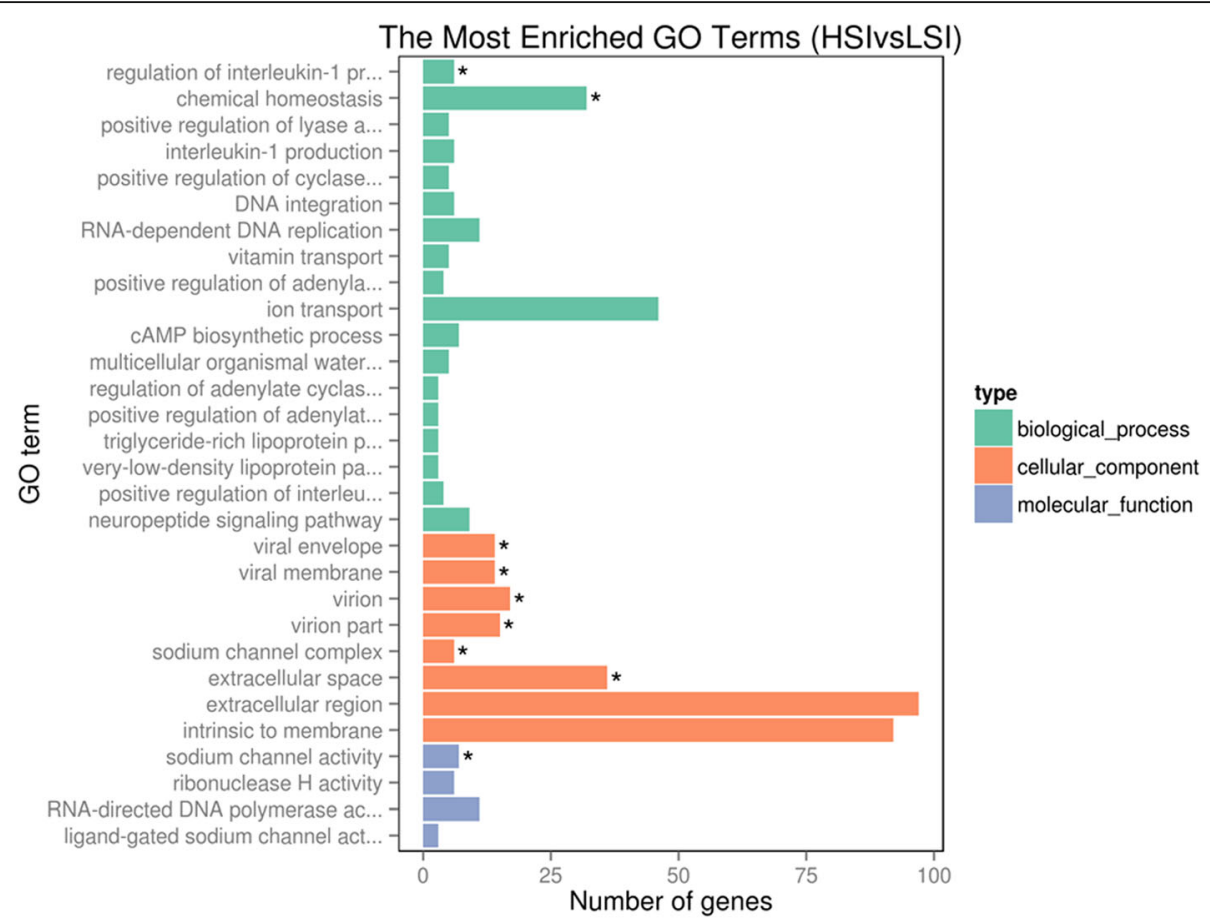

Fig. 3 The enrichment of DEGs in GO terms during the initiation period of calcification (HSI vs. LSI). ${ }^{*}$ means significantly different $(P<0.05)$

during the calcification period has been described in previous studies $[28,29]$. This transcriptome compared gene expression in the uterus collected during the active calcification phase (growth period of calcification), when there is rapid secretion and growth of $\mathrm{CaCO}_{3}$ leading to the formation of the compact shell layer versus the uterus with the absence of egg. However, differences in

Table 3 Significantly enriched KEGG pathways in the initiation period of calcification

\begin{tabular}{llll}
\hline Term & $\begin{array}{l}\text { Gene } \\
\text { number }\end{array}$ & $\begin{array}{l}\text { Background } \\
\text { number }\end{array}$ & $P$-value \\
\hline Linoleic acid metabolism & 6 & 28 & 0.0002 \\
Glycerophospholipid metabolism & 9 & 86 & 0.0009 \\
Alpha-linolenic acid metabolism & 5 & 25 & 0.0011 \\
Drug metabolism, cytochrome P450 & 5 & 29 & 0.0019 \\
Ether lipid metabolism & 5 & 39 & 0.0059 \\
Arachidonic acid metabolism & 5 & 48 & 0.0130 \\
Metabolism of xenobiotics by & 4 & 32 & 0.0148 \\
cytochrome P450 & & & \\
Calcium signaling pathway & 10 & 162 & 0.0166 \\
GnRH signaling pathway & 6 & 77 & 0.0230 \\
Vascular smooth muscle contraction & 7 & 100 & 0.0239 \\
Glycosphingolipid biosynthesis, lacto & 3 & 21 & 0.0250 \\
and neolacto series & & & \\
Phagosome & 8 & 127 & 0.0277 \\
MAPK signaling pathway & 11 & 214 & 0.0382 \\
\hline
\end{tabular}

the uterine transcriptome from hens laying eggs with high and low eggshell breaking strength during synchronous calcification periods have not been reported. The current study identified DEGs in the uterus obtained according to eggshell breaking strength. Few DEGs were observed during the growth and termination periods of calcification, while 1777 genes were differentially expressed during the initiation period. These results suggest that the initiation period have a greater contribution to eggshell strength than the other two periods of calcification. Therefore, we focused our attention on the initiation period and screened 30 DEGs as candidates related to calcification according to KEGG analysis and previous studies (Table 4).

The selected candidate genes were broadly classified into two types: extracellular proteins secreted into uterine fluid (TF, OVAL, etc.), and ion transporter genes in glandular cells (SLC31A1, SLC31A2, etc.). Marie et al. identified 308 proteins in uterine fluid during the initiation, growth, and termination periods of calcification and obtained nine proteins related to calcification in the initiation period, including TF and OVAL [3]. TF and OVAL were also reported to be related to eggshell structure in previous study [44]. This is consistent with the study which TF and OVAL were associated with the structural organization of the mammillary layer and crystal size by genetic associations [45]. In the present study, the gene expression levels of TF and OVAL were significantly higher in the LS. This implied that they 
Table 4 Functions of DEGs related to calcification in the initiation period

\begin{tabular}{|c|c|c|c|}
\hline Gene ID & Gene symbol & $\log _{2}($ fold-change) & Gene description \\
\hline ENSGALG00000000703 & SLC45A3 & -1.20 & myelin-enriched sugar transporter [46] \\
\hline ENSGALG00000010187 & SLC1A1 & -1.27 & glutamate transporter [47] \\
\hline ENSGALG00000003582 & SLC1A3 & 1.03 & glutamate transporter [48] \\
\hline ENSGALG00000005933 & SLC5A11 & 1.13 & sodium-dependent cotransporter [49] \\
\hline ENSGALG00000006194 & SLC52A3 & -1.07 & riboflavin transporter [50] \\
\hline ENSGALG00000007998 & SLC26A4 & -7.57 & chloride-iodide transport protein [51] \\
\hline ENSGALG00000008844 & SLC31A1 & -1.34 & copper transporter [52] \\
\hline ENSGALG00000014372 & SLC34A2 & -4.21 & phosphate transporter [53] \\
\hline ENSGALG00000011003 & SLC35F3 & 1.86 & thiamine transporter [54] \\
\hline ENSGALG00000017032 & SLC25A15 & 1.94 & mitochondrial ornithine carrier [55] \\
\hline ENSGALG00000027743 & SLC4A1 & 2.32 & Bicarbonate transporter [56] \\
\hline ENSGALG00000028756 & SLC4A2 & 0.96 & Bicarbonate transporter [57] \\
\hline ENSGALG00000044387 & SLC4A9 & 2.11 & Bicarbonate transporter [58] \\
\hline ENSGALG00000008045 & SLC9A8 & 0.88 & Sodium/proton exchangers [59] \\
\hline ENSGALG00000001314 & PTGS1 & -1.02 & Catalyse prostaglandin formation \\
\hline ENSGALG00000006453 & TF & -2.20 & Regulate crystal size [45] \\
\hline ENSGALG00000012869 & OVAL & -3.65 & Regulate crystal size [45] \\
\hline ENSGALG00000023622 & $A V D$ & -2.81 & Binding biotin \\
\hline ENSGALG00000010926 & SPP1 & -1.64 & Regulate crystal growth [60] \\
\hline ENSGALG00000002207 & ATP6V1G3 & 1.52 & Proton pump \\
\hline ENSGALG00000015868 & ATP6V0D2 & 1.55 & Proton pump \\
\hline ENSGALG00000016446 & ATP6V1C2 & 0.92 & Proton pump \\
\hline ENSGALG00000011258 & ATP2B1 & -0.86 & Plasma membrane calcium transporter \\
\hline ENSGALG00000007179 & ATP13A5 & 2.23 & $\mathrm{Ca}^{2+}$ homeostasis [61] \\
\hline ENSGALG00000015454 & CA8 & 1.56 & Catalyse $\mathrm{HCO}_{3}^{-}$formation \\
\hline ENSGALG00000006202 & SCNN1B & 1.51 & Epithelial sodium channel [28] \\
\hline ENSGALG00000006270 & SCNN1G & 1.25 & Epithelial sodium channel [28] \\
\hline ENSGALG00000014244 & SCNN1A & 2.07 & Epithelial sodium channel [28] \\
\hline ENSGALG00000009324 & CFTR & 1.22 & Chloride channel [28] \\
\hline ENSGALG00000025804 & CLCN2 & 1.52 & Chloride channel [28] \\
\hline
\end{tabular}

adversely affect the formation of the mammillary layer and reduce eggshell strength. We also observed that the osteopontin (SPP1) gene was significantly upregulated in the LS as compared to HS, which may imply SPP1 damaged eggshell quality. A previous study demonstrating that SPP1 inhibit the growth of calcite crystals in vitro supports this view [60].

GO analysis revealed that many DEGs were enriched in ion transport functions associated with eggshell calcification (Fig. 3). When the eggshell is calcified, it is necessary to maintain sufficient ions in the uterus. Jonchère et al. identified uterine ion transporters in uterine tissue where calcification occurred and when calcification was prevented artificially by expelling the egg during 4 consecutive days previously [28]. A total of 37 ion transport genes were selected and a model of ion transport in uterine glandular cells was provided. The model of ion transport was updated and enriched in later research using the same method [29]. The above studies did not involve eggshell strength, and $\mathrm{Ca}^{2+}$ and $1,25(\mathrm{OH})_{2} \mathrm{D}_{3}$ levels in the blood were affected by expelling the egg. We identified differences in ion transport of the uterus producing high and low breaking strength eggshells during normal calcification. Our aim was to identify the genes affecting eggshell strength. In addition to the common ion transport genes identified in the previous reports, the present study has also described some novel genes involved. The uterine ion transport model was further updated based on the previous studies (Fig. 4).

$\mathrm{Ca}^{2+}$ in uterine fluid is derived from calcium in the blood. TRPV6, CALB1, and ATP2A2/3, which are responsible for $\mathrm{Ca}^{2+}$ transport, were not significantly 


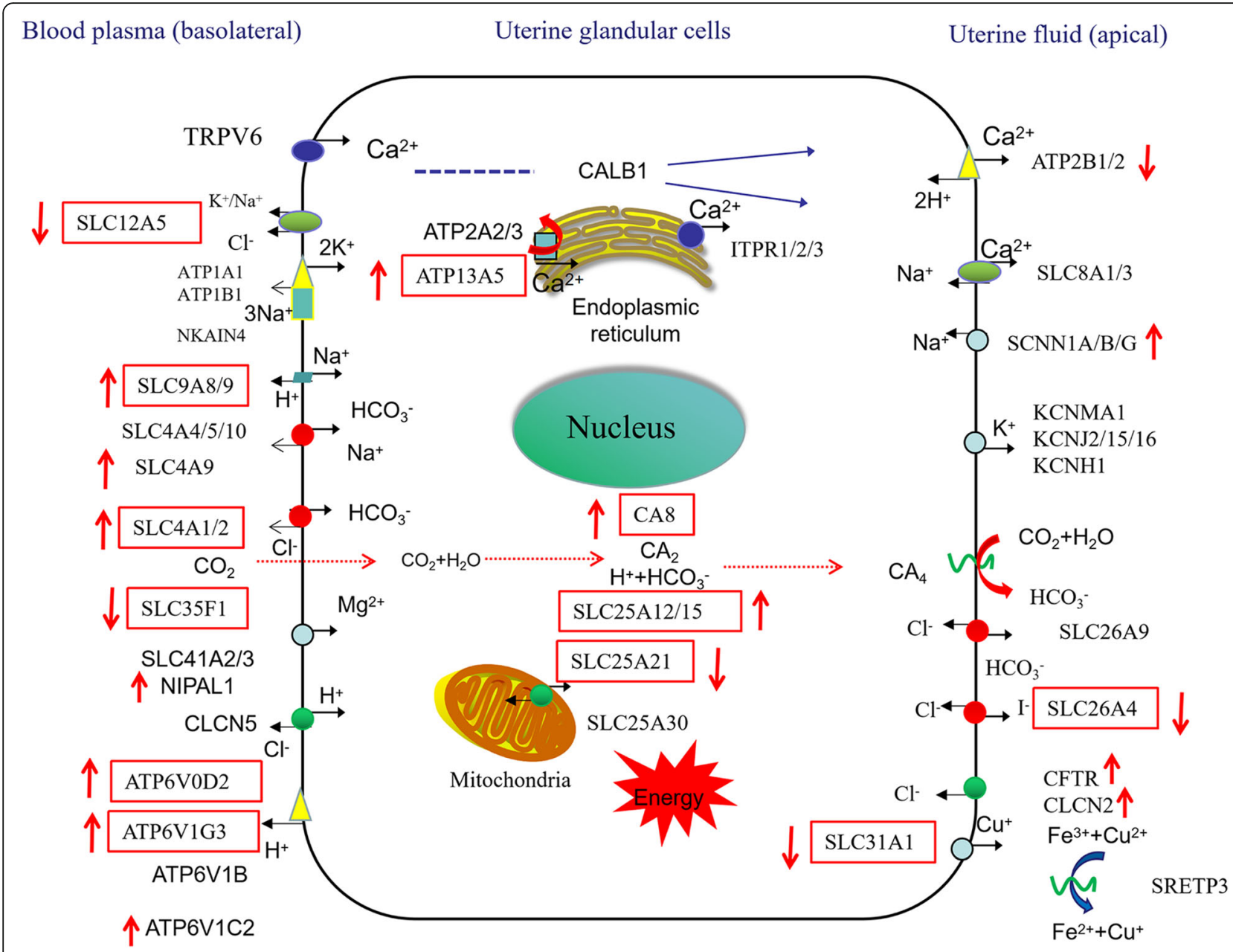

Fig. 4 The updated model of ion transporters in the uterus during the initiation calcification of eggshell. Red squares indicate novel DEGs identified in our study; Upward arrows indicate upregulated genes and downward arrows indicate downregulated genes (HSI vS. LSI)002E

different between groups. However, the endoplasmic reticulum calcium transporter (ATP13A5) was significantly upregulated in the $\mathrm{HS}$ as compared to $\mathrm{LS} . \mathrm{HCO}_{3}{ }^{-}$ in uterine fluid is generated by CAs catalyzing reversible $\mathrm{CO}_{2}$ hydration, and transported to uterine fluid. Immunohistochemical studies have indicated that CAs are present in chicken uterine glandular cells [62] and cytosolic CA 2-14 of Gallus gallus has been referenced in the gene database (NCBI). We observed a high expression level of the CA8 gene in the HS, but no differences in other CAs, suggesting that CA8 may play a pivotal role in the conversion of intracellular $\mathrm{CO}_{2}$ to $\mathrm{HCO}_{3}{ }^{-}$in uterine glandular cells during the initiation period of calcification. Our study showed that the expression levels of the $\mathrm{HCO}_{3}{ }^{-}$transporters SLC4A1, SLC4A2, and SLC4A9 were significantly upregulated in the HS as compared to the LS. This indicates that the supply of $\mathrm{HCO}_{3}{ }^{-}$, rather than $\mathrm{Ca}^{2+}$, affected eggshell quality, even in the LS. This may also explain why eggshell quality could be improved by adding $\mathrm{NaHCO}_{3}$ to the diet [63], rather than increasing dietary calcium levels [15]. During eggshell formation, progressive acidification of uterine fluid and uterine glandular cells occurs. The production of $\mathrm{HCO}_{3}{ }^{-}$is accompanied by the appearance of $\mathrm{H}^{+}$, and the $\mathrm{pH}$ in the uterine fluid is lowered by the generation of $\mathrm{H}^{+}$[64], which inhibits $\mathrm{CaCO}_{3}$ deposition. $\mathrm{H}^{+}$is transported by the proton pumps (ATP6V0D2, ATP6V1G3, ATP6V1B, and ATP6V1C2) to maintain intracellular $\mathrm{pH}$ [65]. The relative expression levels of the proton pumps were significantly upregulated in the HS as compared to the LS, which indicated the ability of the HS to exclude $\mathrm{H}^{+}$was higher than that of the LS.

\section{Conclusions}

In conclusion, our study supported the previous view that mammillary thickness, mammillary knob width, and mammillary layer ratio are significantly lower in the HS. Serum $\mathrm{P}_{4}$ and $1,25-(\mathrm{OH})_{2} \mathrm{D}_{3}$ levels were higher during the initiation period of calcification of the HS. Serum $E_{2}$ and calcium had minor effect on eggshell strength. The 
large differences in the transcriptome proved that the initiation period of calcification determines eggshell strength. The uterine ion transport model was further updated based on previous studies, improving our understanding of the eggshell calcification process.

\section{Materials and methods}

\section{Ethical statement and experimental procedures}

The experimental animal procedure was approved by the Scientific Ethics Committee of Huazhong Agricultural University on 11 May 2017. The ethical approval code is HZAUCH-2017-006. A total of 210 42-week-old Hy-Line Brown laying hens were caged individually and subjected to a $16 \mathrm{~h}: 8 \mathrm{~h}$ light:dark cycle. Hens were fed a layer mash ad libitum as recommended by NRC (1994). The oviposition time per hen was observed and recorded from 5:00 am to 5:00 pm for 10 consecutive days named observation period, which contributed to determine the calcification periods. During the observation period, the eggshell breaking strength of eggs from each hen was determined every day, which contributed to select the hens laid eggs with hard or weak-shell. The laying hens with minor fluctuations in oviposition time (the fluctuation less than $30 \mathrm{~min}$ ) and eggshell breaking strength (the fluctuation less than $4 \mathrm{~N}$ ) were remained and others were discarded. In the remaining laying hens, 30 laying hens laid hard-shelled eggs were selected as high breaking strength group (HS) and 30 laying hens laid weak-shelled eggs were selected as low breaking strength group (LS). The eggshell breaking strength in HS and LS were $44.57 \pm 0.91 \mathrm{~N}$ and $26.68 \pm 0.38 \mathrm{~N}$ (mean $\pm \mathrm{SD}$ ), respectively. The entire process of eggshell calcification in uterus was divided into three calcification periods of $6-8 \mathrm{~h}$ (initiation), 14-16 h (growth), and 20-22 h (termination) after oviposition according to the previous study [3]. 10 hens in each group selected randomly were sampled in each calcification period.

\section{Sample collection}

Three eggs per hen were collected. Blood samples were taken from the wing vein for the three calcification periods of each group. The hens were slaughtered after blood samples were taken. The duodenum, kidney, and uterus were surgically removed, frozen in liquid nitrogen immediately, and stored at $-80^{\circ} \mathrm{C}$. The blood samples were centrifuged (Eppendorf centrifuge 5804R, Hamburg, Germany) at $1000 \times g$ at $4{ }^{\circ} \mathrm{C}$ for $10 \mathrm{~min}$, and the serum was separated and stored at $-80^{\circ} \mathrm{C}$ for analyzing levels of calcium, estrogen $\left(\mathrm{E}_{2}\right)$, progesterone $\left(\mathrm{P}_{4}\right)$, and 1,25-dihydroxy vitamin $\mathrm{D}_{3}\left[1,25-(\mathrm{OH})_{2} \mathrm{D}_{3}\right]$ levels.

\section{Mechanical properties and ultrastructure of eggshells}

Eggshell breaking strength, eggshell thickness, egg weight, and egg shape index were assessed. The length, width, and eggshell thickness of eggs were determined using an electronic digital micrometer (Shanghai Shenhan Measuring Tools Co., Ltd., Shanghai, China). Eggshell breaking strength was determined using an Eggshell Force Gauge (EFG-0503, Robotmation Co., Ltd., Japan). Eggs and eggshells were weighed using an electronic balance (AUY220, Shimadzu Corporation, Kyoto, Japan). The egg shape index was calculated as length/width and the shell ratio was calculated as eggshell weight/egg weight $\times 100 \%$. A total of 10 eggs from each group were selected randomly for scanning ultrastructures using a scanning electron microscope (JSM-6390LV, JEOL Ltd., Tokyo, Japan). The selected eggs were broken manually after being washed with distilled water to remove dirt on the outer surface. The contents of the interior were discarded and the inside of the shell was cleaned with distilled water to remove residual egg white. A piece $\left(1 \mathrm{~cm}^{2}\right)$ of each eggshell was cut from the equatorial region. The eggshell membranes were removed as the previous method reported by Kaplan et al. [66] and used by Gongruttananun et al. [67]. The eggshell fragments without membranes were coated with gold powder and the transverse surface was imaged.

\section{Detection of hormones and calcium levels in the serum}

The concentrations of $E_{2}, P_{4}$, and $1,25-(\mathrm{OH})_{2} \mathrm{D}_{3}$ in the serum were measured using enzyme-linked immunosorbent assay kits (Nanjing Jiancheng Bioengineering Institute, Nanjing, China). The measuring procedures were performed according to the manufacturer's instructions. Serum calcium was detected by atomic absorption spectrophotometer (AA-6300C, Shimadzu Corporation).

\section{RT-qPCR of genes related to calcium translocation in the duodenum}

The relative expressions of calbindin $\left(\mathrm{CaBP}-\mathrm{D}_{28 \mathrm{k}}\right), \mathrm{Na}^{+} /$ $\mathrm{Ca}^{2+}$ exchanger (NCX1), and ATPase plasma membrane $\mathrm{Ca}^{2+}$ transporter (PMCA1b) were used to verify the capacity of calcium absorption in the duodenum. These genes are responsible for calcium ion transport. The primers for RT-qPCR were designed by primer 5.0. Total mRNA was extracted from the uterus with TRIzol reagent (Invitrogen, Carlsbad, CA, USA) according to the manufacturer's instructions. mRNA quality and concentration were determined using a nucleic acid concentration analyzer (NanoDrop 2000, Thermo Fisher Scientific, Waltham, MA, USA) at 260 and $280 \mathrm{~nm}$. Reverse transcription to synthesize the cDNA library was performed using the PrimeScriptTM RT reagent kit (TaKaRa, Japan). Expression levels of candidate genes were analyzed using RT-qPCR analyzer (CFX384, Bio-Rad, Hercules, CA, USA) with SYBR Green Dye (Bio-Rad, USA). After the initial temperature rise to $95^{\circ} \mathrm{C}$, denaturation was performed at $95^{\circ} \mathrm{C}$ for $5 \mathrm{~min}$; all reactions were then subjected to 40 cycles at $95^{\circ} \mathrm{C}$ for $5 \mathrm{~s}$, 
annealing at the appropriate annealing temperature for $30 \mathrm{~s}$, and extension at $72{ }^{\circ} \mathrm{C}$ for $20 \mathrm{~s}$. CT values were normalized using the reference gene ( $\beta$-actin). The fold change was calculated using the $2^{-\Delta \Delta \mathrm{CT}}$ method [68].

\section{Transcriptomics analysis of the uterus}

The uterus samples of the HS and LS were prepared for high throughput sequencing. There were three uterus samples from each calcification period per group, namely, the initiation period in the HS or LS (HSI and LSI, respectively), the growth period in the HS or LS (HSG and LSG, respectively), and the termination period in the HS or LS (HST and LST, respectively). Total mRNA was isolated with TRIzol reagent (Invitrogen). The concentration, quality, and integrity of mRNA were determined using a NanoDrop spectrophotometer (NanoDrop Technologies, Wilmington, DE, USA). RNA library construction and sequencing were performed at Shanghai Personal Biotechnology Co., Ltd. (Shanghai, China). The cDNA libraries were constructed following the TruSeq RNA Sample Preparation Guide (Illumina, San Diego, CA, USA). Poly (A) mRNA was isolated from purified total RNA using biotin-oligo (dT) magnetic beads and fragmented to generate average insert sizes of approximately $350 \mathrm{bp}$ before creating the cDNA libraries. Quality control was conducted using PicoGreen fluorescence spectrophotometry and an Agilent Bioanalyzer (Agilent Technologies, Palo Alto, CA, USA). A cluster was generated, diluted to 4-5 $\mathrm{pM}$, and sequenced using the Illumina NextSeq 500 System with paired-end $2 \times 150$-bp reads.

\section{Validation of differentially expressed genes (DEGs)}

To confirm the accuracy of the RNA sequencing (RNASeq) gene expression data obtained from high throughput sequencing, RT-qPCR was carried out on the 12 selected genes that were considered as candidate genes related to eggshell calcification. RT-qPCR was performed as described above.

\section{Statistical analysis}

All values were analyzed by one-way ANOVA analysis of variance followed by Duncan test. Values were expressed as mean \pm standard error of the mean (SEM) and the analyses were conducted using IBM SPSS Statistics 20 (IBM Corporation, Armonk, NY, USA). $P$ values $<0.05$ were considered statistically significant. The figures were generated using GraphPad Prism 5 (Graph Pad Software Inc., San Diego, CA, USA). Raw RNA-Seq reads were preprocessed, assembled and filtered according to the description in the previous study [69]. Reference genome and gene model annotation files were downloaded from genome website (http://asia.ensembl.org/index.html). Index of the reference genome was built using Bowtie (v2.0.6) [70] and paired-end clean reads were aligned to the reference genome using TopHat (v2.0.9) [71]. HTSeq (v0.6.1) was used to count the reads numbers mapped to each gene [72] and then the reads per kilo base per million reads (RPKM) of each gene was calculated based on the length of the gene and reads count mapped to this gene [73]. Differential expression analysis was performed using the DESeq software (1.10.1) [74]. The resulting P-values were adjusted using the Benjamini and Hochberg's method for controlling the false discovery rate [75]. Genes with fold change $>1.5$ and $P$-value $<0.05$ were identified as DEGs. Gene Ontology (GO) enrichment analysis of DEGs was implemented by the GOseq software (1.10.0) [76], in which gene length bias was corrected. GO terms with corrected $P$-value less than 0.05 were considered significantly enriched by DEGs. KEGG database (http://www.genome. $\mathrm{jp} / \mathrm{kegg} /$ ) and KOBAS software (v2.0.12) were used to test the statistical enrichment of DEGs in KEGG pathways [77].

\section{Additional files}

Additional file 1: Scanning electron microscope images showing the transverse view of eggshellultrastructure from different breaking strength. Figure showing effective layer, mammillary layer, mammillary knob in HS and LS. (PDF $454 \mathrm{~kb}$ )

Additional file 2: The eggs in different calcification periods. Figure showing the differences of eggshell during initiation, growth and termination periods respectively. (PDF $510 \mathrm{~kb}$ )

Additional file 3: The primer sequences of target genes for RT-qPCR in duodenum. Word file giving the primer sequences. (DOC 32 kb)

Additional file 4: DEGs in hen uterus during different period of calcification. Excel file describing the DEGs that were annotated and nonannotated. (XLS 580 kb)

Additional file 5: Primer sequences of candidate genes for RT-qPCR. Word file giving the primer sequences. (DOC $50 \mathrm{~kb}$ )

Additional file 6: Correlation of Log2(fold change) between RNAseq results (abscissa) and $\mathrm{RT}-\mathrm{qPCR}$ results (ordinate). Figure showing the accuracy and reproducibility of the RNA-Seq results. (PDF $206 \mathrm{~kb}$ )

\section{Abbreviations}

1,25-(OH $)_{2} \mathrm{D}_{3}$ : 1,25-dihydroxy vitamin $\mathrm{D}_{3}$; DEGs: Differentially expressed genes; $\mathrm{E}_{2}$ : Estrogen; GO: Gene Ontology; HS: High breaking strength group; HSG: Growth period of calcification in HS; HSI: Initiation period of calcification in HS; HST: Termination period of calcification in HS; KEGG: Kyoto Encyclopedia of Genes and Genomes; LS: Low breaking strength group; LSG: Growth period of calcification in LS; LSI: Initiation period of calcification in LS; LST: Termination period of calcification in LS; NRC: National research council; $P_{4}$ : Progesterone; RT-qPCR: Real time quantitative PCR

\section{Acknowledgements}

Not applicable.

\section{Authors' contributions}

$J Z$ designed the study, carried out the experiments and analyses, wrote the paper. YW, and CZ and MX were involved in the feeding of laying hens and sample collection. SAR and YL contributed to detect mechanical properties of eggshells. DQ provided the strategy and idea, designed experiments and contributed to write the paper. All authors read and approved the final manuscript.

\section{Funding}

The project was funded by the National Natural Science Foundation of China (31572438). 


\section{Availability of data and materials}

The RNA-Seq datasets have been submitted to NCBI Sequence Read Archive (SRA). SRA accession: PRJNA523965.

\section{Ethics approval and consent to participate}

The experiment was approved by the Scientific Ethics Committee of Huazhong Agricultural University. The ethical approval code is HZAUCH-2017-006.

\section{Consent for publication}

Not applicable.

\section{Competing interests}

The authors declare that they have no competing interest.

Received: 5 March 2019 Accepted: 6 August 2019

Published online: 11 September 2019

\section{References}

1. Marie P, Labas V, Brionne A, Harichaux G, Hennequet-Antier C, Nys Y, Gautron J. Data set for the proteomic inventory and quantitative analysis of chicken uterine fluid during eggshell biomineralization. Data Brief. 2014;1: 65-9.

2. Roland DA. Egg shell problems: estimates of incidence and economicimpact. Poult Sci. 1988;67(12):1801-3.

3. Marie $P$, Labas V, Brionne A, Harichaux G, Hennequet-Antier C, Nys Y, Gautron J. Quantitative proteomics and bioinformatic analysis provide new insight into protein function during avian eggshell biomineralization. J Proteome. 2015;126:140-54.

4. Carnarius KM, Conrad KM, Mast MG, Macneil JH. Relationship of eggshell ultrastructure and shell strength to the soundness of shell eggs. Poul Sci. 1996;75:656-63.

5. Ahmed AMH, Rodriguez-Navarro AB, Vidal ML, Gautron J, García-Ruiz JM Nys Y. Changes in eggshell mechanical properties, crystallographic texture and in matrix proteins induced by moult in hens. Br Poult Sci. 2005;46(3): 268-79.

6. Zhang YN, Zhang HJ, Wu SG, Wang J, Qi GH. Dietary manganese supplementation modulated mechanical and ultrastructural changes during eggshell formation in laying hens. Poult Sci. 2017:96(8):2699-707.

7. Stefanello C, Santos TC, Murakami AE, Martins EN, Carneiro TC. Productive performance, eggshell quality, and eggshell ultrastructure of laying hens fed diets supplemented with organic trace minerals. Poult Sci. 2014;93(1):104-13.

8. Nys $Y$, Hincke M, Hernandez-Hernandez A, Rodriguez-Navarro A, GomezMorales J, Jonchere V, Garcia-Ruiz J, Gautron J. Eggshell ultrastructure, properties and the process of mineralization: involvement of organic matrix in the eggshell fabric. Prod Anim. 2010;23(2):143-54.

9. Nys Y, Gautron J, Garcia-Ruiz JM, Hincke MT. Avian eggshell mineralization: biochemical and functional characterization of matrix proteins. C R Palevol. 2004;3:549-62.

10. Hincke MT, Gautron JL, Charles PWT, McKee MD, Nys Y. Molecular cloning and ultrastructural localization of the core protein of an eggshell matrix proteoglycan, Ovocleidin-116. J Biol Chem. 1999;274(46):32915-23.

11. Hincke MT, Tsang CP, Courtney M, Hill V, Narbaitz R. Purification and immunochemistry of a soluble matrix protein of the chicken eggshell (ovocleidin 17). Calcif Tissue Int. 1995;56(6):578-83.

12. Gautron J, Hincke MT. Ovocalyxin-32, a novel chicken eggshell matrix protein - isolation, amino acid sequencing, cloning, andimmunocytochemical localization. J Biol Chem. 2001;276(42):39243-52.

13. Gautron J, Murayama E, Vignal A, Morisson M, McKee MD, Réhault S, Labas V, Belghazi M, Vidal M, Nys Y, Hincke MT. Cloning of Ovocalyxin-36, a novel chicken eggshell protein related to lipopolysaccharide-binding proteins, bactericidal permeability-increasing proteins, and plunc family proteins. J Biol Chem. 2007;282(8):5273-86.

14. Mann K. The calcified eggshell matrix proteome of a songbird, the zebra finch (Taeniopygia guttata). Proteome Sci. 2015;13:29.

15. Świątkiewicz S, Arczewska-Włosek A, Krawczyk J, Puchała M, Józefiak D. Effects on performance and eggshell quality of particle size of calcium sources in laying hens' diets with different ca concentrations. Arch Anim Breed. 2015;58:301-7.

16. Xiao JF, Zhang YN, Wu SG, Zhang HJ, Yue HY, Qi GH. Manganese supplementation enhances the synthesis of glycosaminoglycan in eggshell membrane: a strategy to improve eggshell quality in laying hens. Poult Sci. 2014;93(2):380-8.

17. Mabe I, Rapp C, Bain MM, Nys Y. Supplementation of a corn-soybean meal diet with manganese, copper, and zinc from organic or inorganic sources improves eggshell quality in aged laying hens. Poult Sci. 2003;82(12):1903-13.

18. Zamani A, Rahmani HR, Pourreza J. Supplementation of a corn-soybean meal diet with manganese and zinc improves eggshell quality in laying hens. Pak J Biol Sci. 2005;8(9):1311-7.

19. Swiatkiewicz $\mathrm{S}$, Koreleski J. The effect of zinc and manganese source in the diet for laying hens on eggshell and bones quality. Vet Med. 2008;53(10): $555-63$.

20. Świątkiewicz S, Koreleski J. Eggshell quality in laying hens fed diets supplemented with different levels of zinc and manganese. Pol J Food Nutr Sci. 2007;57(4):551-4.

21. Kim CH, Paik IK, Kil DY. Effects of increasing supplementation of magnesium in diets on productive performance and eggshell quality of aged laying hens. Biol Trace Elem Res. 2013;151:38-42.

22. Lim HS, Paik IK. Effects of supplementary mineral methionine chelates (Zn, $\mathrm{Cu}, \mathrm{Mn}$ ) on the performance and eggshell quality of laying hens. Asian Australas J Anim Sic. 2003;16(12):1804-8.

23. Chowdhury SD. Shell membrane protein system in relation to lathyrogen toxicity and copper deficiency. Worlds Poult Sci J. 1990;46(2):153-69.

24. Wistedt A, Ridderstrale Y, Wall H, Holm L. Exogenous estradiol improves shell strength in laying hens at the end of the laying period. Acta Vet Scand. 2014:56:34.

25. Bar A, Vax E, Hunziker W, Halevy O, Striem S. The role of gonadal hormones in gene expression of calbindin (Mr 28,000) in the laying hen. Gen Comp Endocrinol. 1996;103:115-22.

26. Lundholm CE. Increased eggshell thickness in domestic fowls after administration of the antiprogesterone RU 38486 (mifepristone). Pharmacol toxicol. 1990;67(2):185-7.

27. Liu H, Bacon WL. Changes in egg production rate induced by progesterone injection in broiler breeder hens. Poult Sci. 2005;84(2):321-7.

28. Jonchere V, Brionne A, Gautron J, Nys Y. Identification of uterine ion transporters for mineralisation precursors of the avian eggshell. BMC Physiol. 2012;12:10.

29. Brionne A, Nys Y, Hennequet-Antier C, Gautron J. Hen uterine gene expression profiling during eggshell formation reveals putative proteins involved in the supply of minerals or in the shell mineralization process. BMC Genomics. 2014;15:220.

30. Bahadoran S, Dehghani Samani A, Hassanpour H. Effect of heat stress on the gene expression of ion transporters/channels in the uterus of laying hens during eggshell formation. Stress. 2018;21(1):51-8.

31. Rodriguez-Navarro A, Kalin O, Nys Y, Garcia-Ruiz JM. Influence of the microstructure on the shell strength of eggs laid by hens of different ages. Brit Poult Sci. 2002;43(3):395-403.

32. Meyer R, Baker RC, Scott ML. Effects of hen egg-shell and other calcium sources upon egg-shell strength and ultrastructure. Poult Sci. 1973;52(3):949-55.

33. Jonchère V, Réhault-Godbert S, Hennequet-Antier C, Cabau C, Sibut V, Cogburn $L A$, Nys $Y$, Gautron J. Gene expression profiling to identify eggshell proteins involved in physical defense of the chicken egg. BMC Genomics. 2010;11:57.

34. Vantoledo B, Parsons AH, Combs GF. Role of ultrastructure in determining eggshell strength. Poult Sci. 1982;61 (3):569-72.

35. Bar A, Vax E, Striem S. Relationships among age, eggshell thickness and vitamin D metabolism and its expression in the laying hen. Comp Biochem Physiol A. 1999:123(2):147-54.

36. Nys Y, N'Guyen TM, Williams J, Etches RJ: Blood levels of ionized calcium, inorganic phosphorus, 1,25-dihydroxycholecalciferol and gonadal hormones in hens laying hard-shelled or shell-less eggs. J Endocrinol 1986, 111(1):151-157.

37. Haynes NB, Cooper KJ, Kay MJ. Plasma progesterone concentration in the hen in relation to the ovulatory cycle. Br Poult Sci. 1973;14(4):349-57.

38. Bronneberg RGG, Taverne MAM, Dieleman SJ, Decuypere E, Bruggeman V, Vernooij JCM, Stegeman JA. The relation between ultrasonographic observations in the oviduct and plasma progesterone, luteinizing hormone and estradiol during the egg laying cycle in ostriches. Domest Anim Endocrin. 2007;32(1):15-28.

39. Nys Y. Progesterone and testosterone elicit increases in the duration of shell formation in domestic hens. Br Poult Sci. 1987;28(1):57-68.

40. Moreki JC, Merwe HJVD, Hayes JP. Effect of dietary calcium level on egg production and eggshell quality in broiler breeder hens from 36 to 60 weeks of age. Onl J Anim Feed Res. 2011;1(1):1-7. 
41. Yosefi S, Braw R, Bar A. Intestinal and eggshell calbindin, and bone ash of laying hens as influenced by age and molting. Comp Biochem A Mol Integr Physiol. 2003;136(3):673-82.

42. Berry WD, Brake J. Induced molt increases eggshell quality and Calbindin$D_{28 k}$ content of eggshell gland and duodenum of aging hens. Poult Sic. 1991;70(3):655-7.

43. Bar A, Striem S, Rosenberg J, Hurwitz S. Egg shell quality and cholecalciferol metabolism in aged laying hens. J Nutr. 1988;118(8):1018-23.

44. Ahmed AMH, Rodriguez-Navarro AB, Vidal ML, Gautron J, García-Ruiz JM, Nys Y. Changes in eggshell mechanical properties, crystallographic texture and in matrix proteins induced by moult in hens. Br Poult Sci. 2010;46(3): 268-79.

45. Dunn IC, Rodríguez-Navarro AB, Mcdade K, Schmutz M, Preisinger $R$, Waddington D, Wilson PW, Bain MM. Genetic variation in eggshell crystal size and orientation is large and these traits are correlated with shell thickness and are associated with eggshell matrix protein markers. Anim Genet. 2011;43(4):410-8.

46. Shin D, Howng SYB, Ptáček LJ. Fu YH: miR-32 and its target SLC45A3 regulate the lipid metabolism of oligodendrocytes and myelin. Neuroscience. 2012;213:29-37.

47. Arnold PD, Sicard T, Burroughs E, Richter MA, Kennedy JL. Glutamate transporter gene SLC1A1 associated with obsessive-compulsive disorder. Arch Gen Psychiatry. 2006;63(7):769-76.

48. Turic D, Langley K, Williams H, Norton N, Williams NM, Moskvina V, Van MB, Owen MJ, Thapar A, Donovan MC. A family based study implicates solute carrier family 1-member 3 (SLC1A3) gene in attention-deficit/hyperactivity disorder. Biol Psychiatry. 2005;57(11):1461-6.

49. Tsai L, Hsiao S, Tsai L, Lin C, Tsai J, Liou D, Lan J. The sodium-dependent glucose cotransporter SLC5A11 as an autoimmune modifier gene in SLE. Tissue Antigens. 2008;71(2):114-26.

50. Long L, Pang X, Lei F, Zhang J, Wang W, Liao L, Xu X, He J, Wu J, Wu Z, Wang L, Lin D, Li E, Xu L. SLC52A3 expression is activated by NF-kB p65/Rel$B$ and serves as a prognostic biomarker in esophageal cancer. Cell Mol Life Sci. 2018;75(14):2643-61.

51. Kreman TM, Karniski LP, Wang R, Scott DA, Sheffield VC. The Pendred syndrome gene encodes a chloride-iodide transport protein. Nat Genet. 1999;21(4):440-3.

52. Anchordoquy JP, Anchordoquy JM, Pascua AM, Nikoloff N, Peral-García P, Furnus CC. The copper transporter (SLC31A1/CTR1) is expressed in bovine spermatozoa and oocytes: copper in IVF medium improves sperm quality. Theriogenology. 2017;97:124-33.

53. Shojaiefard M, Lang F. Stimulation of the intestinal phosphate transporter SLC34A2 by the protein kinase mTOR. Biochem Bioph Res Commun. 2006: 345(4):1611-4.

54. Zang X, Han W, Yang F, Ji K, Wang J, Gao P, He G, Wu S. Association of a SNP in SLC35F3 gene with the risk of hypertension in a Chinese han population. Front Genet. 2016;7:108-13.

55. Marobbio CMT, Punzi G, Pierri CL, Palmieri L, Calvello R, Panaro MA, Palmieri F. Pathogenic potential of SLC25A15 mutations assessed by transport assays and complementation of Saccharomyces cerevisiae ORT1 null mutant. Mol Genet Metab. 2015;115(1):27-32.

56. Gabrielli MG, Cox JV, Materazzi G, Menghi G. Cell type-specific and developmentally regulated expression of the AE1 anion exchanger in the chicken chorioallantoic membrane. Histochem Cell Biol. 2004;121(3):189-99.

57. Cox KH, Adair-Kirk TL, Cox JV. Variant AE2 anion exchanger transcripts accumulate in multiple cell types in the chicken gastric epithelium. J Biol Chem. 1996;271(15):8895-902.

58. Lipovich L, Lynch ED, Ming KL, King MC. A novel sodium bicarbonate cotransporter-like gene in an ancient duplicated region: SLC4A9 at 5q31. Genome Biol. 2001;2(4):1-13.

59. Orlowski J, Grinstein S. Diversity of the mammalian sodium/proton exchanger SLC9 gene family. Pflugers Arch. 2004;447(5):549-65.

60. Chien YC, Hincke MT, Vali H, McKee MD. Ultrastructural matrix-mineral relationships in avian eggshell, and effects of osteopontin on calcite growth in vitro. J Struct Biol. 2008;163(1):84-99.

61. Weingarten L, Dave H, Li H, Crawford D. Developmental expression of P5 ATPase mRNA in the mouse. Cell Mol Biol Lett. 2012;17(1):153-70.

62. Gay CV, Faleski EJ, Schraer H, Schraer R. Localization of carbonic anhydrase in avian gastric mucosa, shell gland and bone by immunohistochemistry. J Histochem Cytochem. 1974;22(8):819-25.

63. Jiang MJ, Zhao JP, Jiao HC, Wang XJ, Zhang Q, Lin H. Dietary supplementation with sodium bicarbonate improves calcium absorption and eggshell quality of laying hens during peak production. Br Poult Sci. 2015;56(6):740-7.

64. Nys Y, Zawadzki J, Gautron J, Mills AD. Whitening of brown-shelled eggs: mineral composition of uterine fluid and rate of protoporphyrin deposition. Poult Sci. 1991;70(5):1236-45.

65. Beyenbach KW. The V-type $\mathrm{H}^{+}$ATPase: molecular structure and function, physiological roles and regulation. J Exp Biol. 2006;209(4):577-89.

66. Kaplan S, Siegesmund KA. The structure of the chicken egg shell and shell membranes as studied with the scanning electron microscope and energy dispersive x-ray microanalysis. Poult Sci. 1973;52(5):1798-801.

67. Gongruttananun N. Influence of red light on reproductive performance, eggshell ultrastructure, and eye morphology in Thai-native hens. Poult Sci. 2011;90(12):2855-63.

68. Livak KJ, Schmittgen TD. Analysis of relative gene expression data using realtime quantitative PCR and the $2^{-\Delta \Delta C T}$ method. Methods. 2001;25(4):402-8.

69. Luo JJ, Zhang Y, Sun H, Wei JT, Khalil MM, Wang YW, Dai JF, Zhang NY, Qi DS, Sun LH. The response of glandular gastric transcriptome to T-2 toxin in chick. Food Chem Toxicol. 2019;132:110658.

70. Langmead B, Salzberg SL. Fast gapped-read alignment with bowtie 2. Nat Methods. 2012;9(4):357-9.

71. Trapnell C, Pachter L, Salzberg SL. TopHat: discovering splice junctions with RNA-Seq. Bioinformatics. 2009;25(9):1105-11.

72. Anders S, Pyl PT, Huber W. HTSeq-a Python framework to work with highthroughput sequencing data. Bioinformatics. 2015;31(2):166-9.

73. Mortazavi A, Williams BA, McCue K, Schaeffer L, Wold B. Mapping and quantifying mammalian transcriptomes by RNA-Seq. Nat Methods. 2008; 5(7):621-8.

74. Anders S, Huber W. Differential expression analysis for sequence count data. Genome Biol. 2010;11(10):R106.

75. Benjamini Y, Hochberg Y. On the adaptive control of the false discovery rate in multiple testing with independent statistics. J Educ Behav Stat. 2000; 25(1):60-83.

76. Young MD, Wakefield MJ, Smyth GK, Oshlack A. Method gene ontology analysis for RNA-seq: accounting for selection bias. Genome Biol. 2010;11(2):R14.

77. Kanehisa M, Araki M, Goto S, Hattori M, Hirakawa M, Itoh M, Katayama T, Kawashima S, Okuda S, Tokimatsu T, Yamanishi Y. KEGG for linking genomes to life and the environment. Nucleic Acids Res. 2008;36(1):D480-4.

\section{Publisher's Note}

Springer Nature remains neutral with regard to jurisdictional claims in published maps and institutional affiliations.

Ready to submit your research? Choose BMC and benefit from:

- fast, convenient online submission

- thorough peer review by experienced researchers in your field

- rapid publication on acceptance

- support for research data, including large and complex data types

- gold Open Access which fosters wider collaboration and increased citations

- maximum visibility for your research: over $100 \mathrm{M}$ website views per year

At BMC, research is always in progress.

Learn more biomedcentral.com/submissions 